\title{
Does Environmental Suitability Explain the Relative Abundance of the Tailed Tailless Bat, Anoura caudifer?
}

\author{
Marcelo de Moraes Weber ${ }^{1}$ \& Carlos Eduardo Viveiros Grelle ${ }^{2 \star}$
}

\author{
${ }^{1}$ Programa de Pós-graduação em Ecologia, Instituto de Biologia, Universidade Federal do Rio de Janeiro - UFRJ, \\ Rio de Janeiro, RJ, Brasil \\ ${ }^{2}$ Laboratório de Vertebrados, Departamento de Ecologia, Universidade Federal do Rio de Janeiro - UFRJ, \\ Rio de Janeiro, RJ, Brasil
}

\begin{abstract}
Ecological niche modeling (ENM) can be used to find areas of high environmental suitability, which are used as a surrogate of abundance's estimation. However, the relationship between environmental suitability and local abundance has been rarely tested. In this study we tested this relationship for the nectar-feeding bat Anoura caudifer. We ran an ENM using Maxent with 235 presence records and seven environmental variables to obtain suitability values, gathering relative abundance data for 24 sites from published studies. We found a very strong relationship between abundance and suitability for $A$. caudifer, with suitability predicting $64 \%$ of the spatial variation of abundance. When ENM is correlated with spatial variation of abundance, it can be used as a proxy to forecast the impact of changing climate on abundance. We suggest that the positive relationship found for this common species may be applied to rare nectarivore bat species, helping to guide new surveys and to find unknown populations.
\end{abstract}

Key words: Ecological Niche Modeling, Habitat Specialist Species, Maxent, Nectar-feeding Bat, Relative Abundance.

\section{Introduction}

Understanding species abundance variation across geographic space is one of the main themes in Ecology (Krebs 2008). Many species show large variations in abundance in different parts of their geographic range, being more abundant in some places than in others. Abundance is considered to be an indicator of habitat quality, reflecting factors such as reproductive success, longevity and susceptibility of populations to extinction (e.g. Morrison et al. 2006). One possible pattern found in geographic variation in abundance is that high abundances are found at the core of the species range, declining toward the range boundaries (Brown 1984). Although this pattern is generally assumed in most studies, it was rarely tested (Jiménez-Valverde 2011). Brown (1984) suggested that the pattern of variation in abundance over the geographic range follows three assumptions: (i) abundance reflects the response of local populations to local conditions; (ii) these local conditions must meet the Hutchinsonian niche requirements of the species; and (iii) that environmental conditions that drive local abundance are spatially autocorrelated. Therefore,

\footnotetext{
^Send correspondence to: Carlos Eduardo Viveiros Grelle Laboratório de Vertebrados, Departamento de Ecologia, Universidade Federal do Rio de Janeiro - UFRJ,

CP 68020, CEP 21941-590,

Rio de Janeiro, RJ, Brasil

E-mail: grellece@biologia.ufrj.br
}

environmental variables play a main role in spatial variation of abundance, as already suggested years ago (Taylor \& Taylor 1979), and it can be directly linked to physical factors such as temperature and rainfall, being the highest abundances expected in the optimal abiotic conditions (Krebs 2008).

Currently, it has been very common the use of climatic variables with species occurrence data to predict species distribution over geographic space. In addition to this fundamental application, ecological niche modeling (ENM), or species distribution modeling (SDM), can be used to forecast some events such as the ability of invasion by exotic species in new territories and species responses to global warming (e.g. Peterson et al. 2011). There are several methods to model species distribution, but the most commonly used now is the maximum entropy approach (Maxent; Phillips et al. 2006). Maxent output provides a species' distribution model of environmental suitability in the geographic space, which ranges from 0 (unsuitable) to 1 (highly suitable), based on the environmental variables included in the modeling. These areas of high suitability can be interpreted as areas where the environmental conditions meet the niche requirements of species (Pearson et al. 2007) and they are used as a surrogate of abundance's estimation (Thuiller et al. 2010). Consequently, identifying these suitable areas can indicate, for instance, where a new protected area should be established or where a given exotic species is more prone to invade. 
The underlying assumption for using ENM's environmental suitability in conservation is that highly suitable areas hold high species abundance. Despite the widespread use of ENM and its potential for predicting abundance, the relationship between environmental suitability and local abundance (or density) has been few tested, and the studies show both positive and non-significant results. For instance, Tôrres et al. (2012) studied this relationship for the jaguar (Panthera onca), using several ENM methods, and found that the relationship between density and suitability is better described by a triangular constraint envelope than by a positive and linear relationship (i.e., low jaguar densities occurred both in areas of high and low suitability, but high densities occurred mostly in areas of high suitability). On the other hand, Pearce \& Ferrier (2001) found a positive relationship between abundance and suitability only for 12 of the 73 species modeled, including reptiles, birds, marsupials, and plants. These examples indicate that we are far from a general pattern regarding this controversial subject (Jiménez-Valverde 2011). Therefore, testing if suitability can explain abundance may support or not if environmental suitability can be applied as a surrogate to the management and establishment of conservation units, helping conservationists to apply limited funding resources to species conservation. Then, it is important to test potential relationships between occurrence and abundance, examining where and when such relationships may hold true (Nielsen et al. 2005).

The tailed tailless bat, Anoura caudifer (Geoffroy SaintHilaire, 1818) (Chiroptera, Phyllostomidae) is a nectarivore species and endemic of the South America and it occurs mostly in the Atlantic, Amazonian, and Andean forests (Barquez \& Diaz 2008). A. caudifer is commonly caught in bat surveys using mist nets, thus providing both occupancy and abundance data across its geographical distribution. Considering its large number of records and abundance data, it can be an excellent model-organism to test the relationship between abundance and suitability. If this relationship is true for a common bat species, an ENM can be applied as a surrogate of abundance for rare nectarivore bat species indicating were researchers and conservationists may find unknown populations.

Given the ecological complexity of spatial variation in abundance (e.g. Taylor \& Taylor 1979), and the poor current knowledge about the abundance-suitability relationship, new tests are needed to build a general picture regarding this subject, being this study the first test of this relationship for a bat species. Hence, our working hypothesis was that abundance of Anoura caudifer is functionally related to environmental conditions. If that hold true we should expect (i) a positive correlation between relative abundance and environmental suitability, and (ii) a causal relationship of environmental suitability on relative abundance.

\section{Material and Methods}

\section{Species distribution modeling}

We compiled 235 occurrence data of $A$. caudifer from specialized papers and books published up to 2011 (Figure 1). For records that had locality information but lacked geographic coordinates, we georeferenced sites using Google Earth (Keyhole Inc.) and used the county central coordinates for those localities we could not find. Anoura caudifer distribution modeling was generated using Maxent 3.3.k version (Phillips et al. 2006) with six environmental variables (temperature seasonality, maximum temperature of warmest month, minimum temperature of coldest month, precipitation of wettest month, precipitation of driest month, and precipitation seasonality) derived from Hijmans et al. (2005), and one topographic variable (digital elevation model) from the Hydro-1K dataset (USGS, 2001). All variables had a spatial resolution of $30 "(\sim 1 \mathrm{~km})$. We selected these environmental variables because they are biologically relevant to species distribution and show low collinearity (Souza et al. 2011).

Before running the model, we partitioned randomly the set of occurrence localities in two subsets, one with $75 \%$ of the occurrence data as training data and the remaining $25 \%$ as testing data to evaluate the performance of the resulting model.We used the Area Under the receiver operating characteristic Curve (AUC) to measure the accuracy of both training and testing models of the ENM. AUC value close to 0.50 indicates that the model has no predictive ability whereas AUC value close to one indicates that the model had a good to excellent performance, and we can discriminate properly between suitable and unsuitable areas (Dudík et al. 2004).

\section{Abundance and environmental suitability data for Anoura caudifer}

To obtain local abundance data for A. caudifer throughout its distribution, we gathered all studies published about bat community structure where it was caught. As most studies provide number of captures for all recorded species, including carnivore and insectivore species, we calculated the relative abundance considering only the nectarivore species. As trophic guilds can differ in the way they move and obtain resources, differences in their detectability are expected. Thus, we estimated the proportion of nectarivore species detected in each study (Meyer et al. 2011). Because there is no reliable method to measure the absolute population density of bats, we calculated the relative abundance of the nectarivores according to Arita (1993), dividing the number of captures of A. caudifer by the overall number of nectarivores. To standardize the method, we considered only those specimens captured with mist nets in the understory, excluding those individuals caught in the canopy and collected from roosting sites (e.g. caves and roofs). After calculating the relative abundance of nectarivore species, we selected only those data about $A$. caudifer. After that, we 


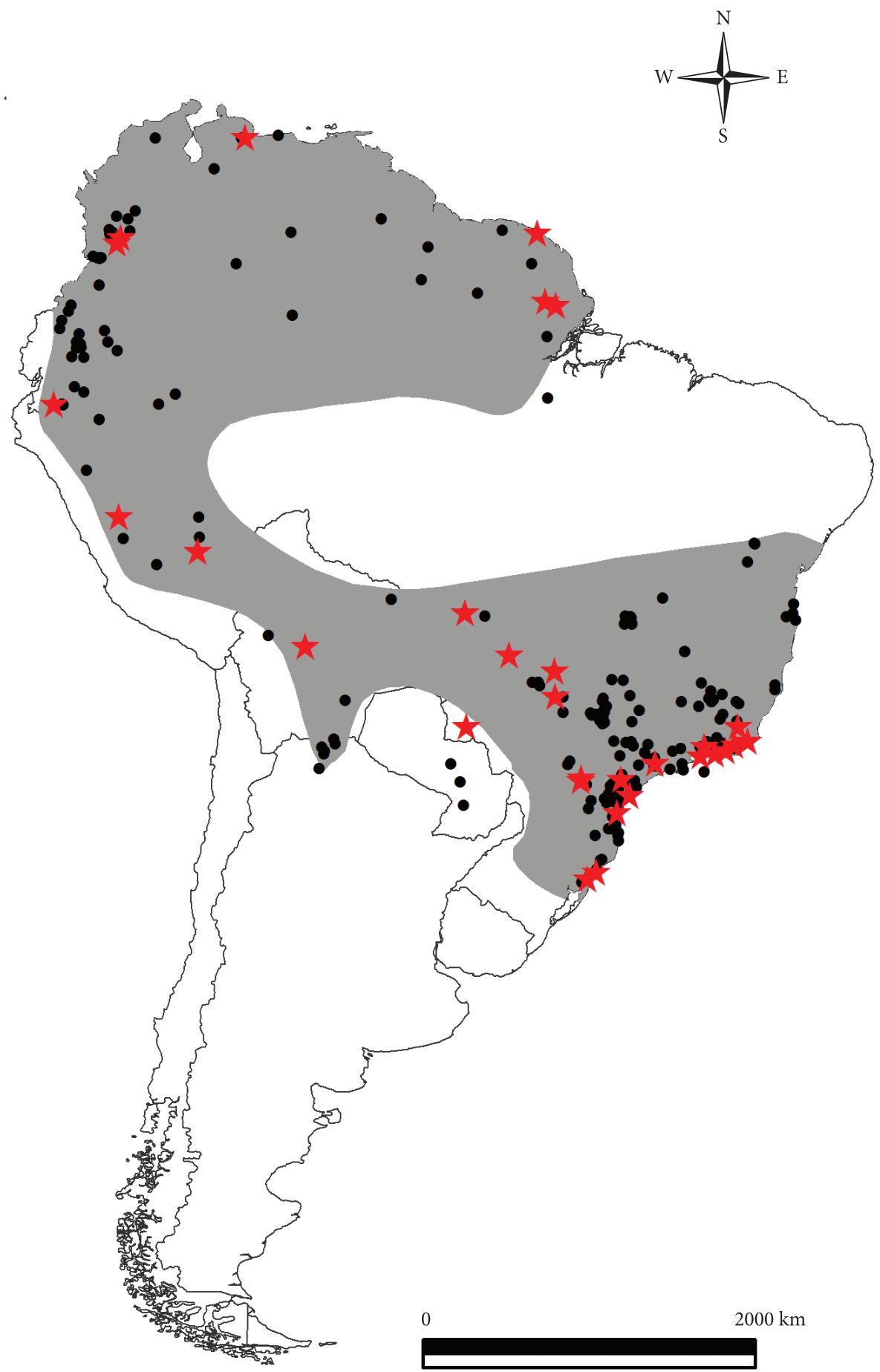

Figure 1. Maps showing the 235 localities of occurrence of the tailed tailless bat, Anoura caudifer, gathered by literature review and used in the species distribution modeling (black circles) and the 24 localities of abundance data (red stars) obtained from literature review. Original distribution of A. caudifer is shown in gray (Barquez \& Diaz 2008).

excluded those data which had relative abundance equal to one to control sources of variation. We did so because of two reasons: (i) a relative abundance of one may indicate that the community was not well sampled, or (ii) the study was carried out at the border of the A. caudifer's distribution, and the metric used by us could overestimate the relative abundance in these areas. At last, we obtained local relative abundance data for 24 sites (Figure 1; see references used in Additional Supporting Information available at www. abeco.org.br). 
Finally, to obtain the suitability data, we overlapped the localities with abundance data on the A. caudifer distribution model. We then extracted the suitability value for each abundance locality using DIVA-GIS 7.4.0.1 (http://www. diva-gis.org/), generating a matrix of local relative abundance and environmental suitability.

\section{Statistical analyses}

Previous studies showed that high abundances can occur in areas of low environmental suitability because there are factors other than climate that influence abundance variation (Tôrres et al. 2012). To evaluate this, we divided the relative abundance values in two groups (high and low) by the median value, according to Tôrres et al. (2012). We compared differences in the mean of suitability values between localities of high and low abundance using a t-test. We also compared suitability variance between areas of high and low abundance using an F-test. These analyses allow us to test heteroscedasticity in the relationship between relative abundance and environmental suitability, choosing properly the best analysis to deal with differences when present. These tests are complementary analysis, because if there is a strong and linear relationship between relative abundance and environmental suitability, then we should find that areas of low abundance have lower mean suitability value than areas of high abundance.
Environmental variables used to generate the environmental suitability map tend to be spatially autocorrelated, and the main problem is that not considering autocorrelation in statistical analyses can increase the Type-I error (Legendre \& Legendre 2003). One way to assess the effects of spatial autocorrelation on a regression model is to check the spatial structure of the residuals, for example using Moran's $I$ coefficient calculated for several distance classes (forming a correlogram). Therefore, before interpreting regression results, we checked the spatial structure of the residuals from the linear regression between abundance and suitability. As Moran's $I$ showed very low values in the first $(I=-0.033)$ and last distance classes $(I=0.014)$, we followed up with the standard simple linear regression analysis to test the abundance-suitability relationship. Spatial autocorrelation analysis and linear regression were performed using SAM 4.0 (Rangel et al. 2010).

\section{Results}

Both training and testing (AUCs equal to 0.921 and 0.898 , respectively) modeling had excellent predictive performance. Highly suitable areas for Anoura caudifer are mostly in the Atlantic Forest in southeastern Brazil and northward Andes. Amazonian Forest included areas of very low suitability (Figure 2)

Environmental suitability differed in mean between areas of high and low abundance $(\mathrm{t}=6.16, P<0.001)$, with areas
Suitability values

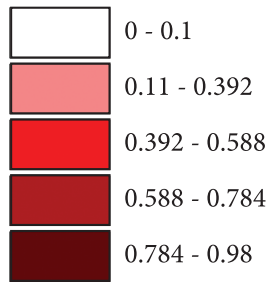

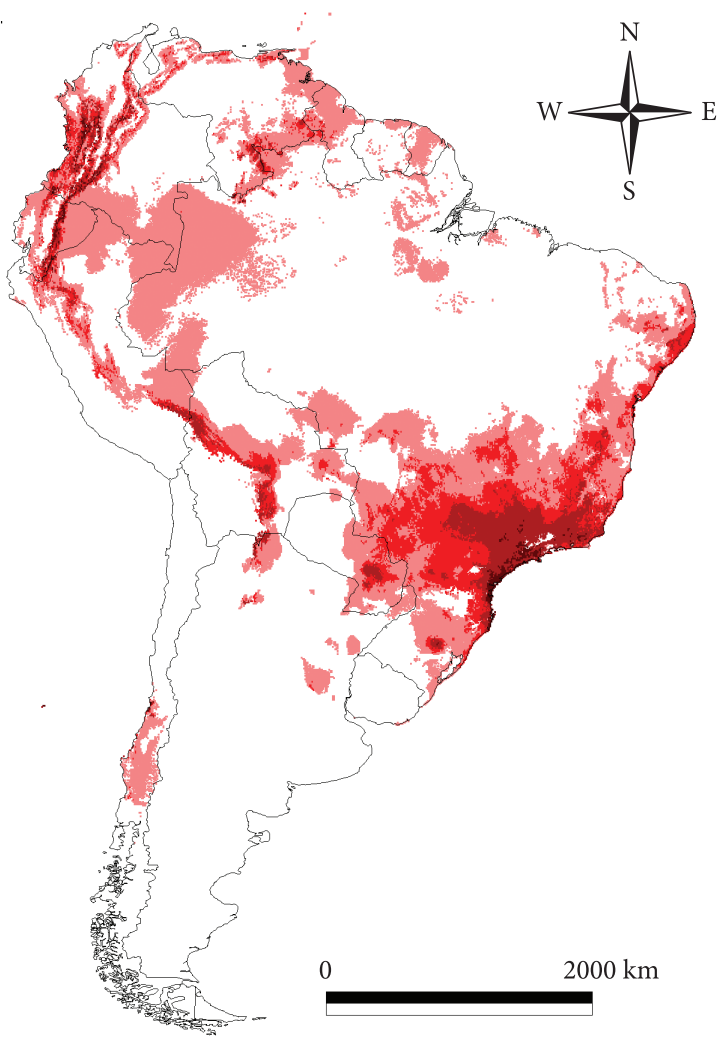

Figure 2. Map showing potential geographical distribution for the tailed tailless bat, Anoura caudifer, modeled with Maxent using seven environmental variables. High environmental suitability areas are shown in dark red. 
of high abundance being more suitable $(0.68 \pm 0.13$ [sd] $)$ than areas of low abundance $(0.29 \pm 0.17[\mathrm{sd}])$. However, suitability variance did not differ between areas of high and low abundance $(F=0.53, P=0.31)$.

A very strong and positive correlation between suitability and local relative abundance is observed, with environmental suitability explaining $64 \%$ of the relative abundance variance of $A$. caudifer $\left(R^{2}=0.64, \mathrm{r}=0.8, P<0.001\right.$; Figure 3$)$.

\section{Discussion}

We found a strong and linear relationship between environmental suitability from presence-only distribution model and spatial variation in the relative abundance of Anoura caudifer, with a great amount of variation in relative abundance (64\%) explained by environmental suitability. To understand the spatial variation in abundance we need to know the physical conditions, resources availability, and influence of competitors and predators on a given species. The strong relationship between environmental suitability and relative abundance for $A$. caudifer found here indicates that the climate regulates mostly its abundance over the geographic space affecting birth, death, and movement rates. The movement is particularly interesting to bats because they are highly mobile and can move toward sites of better environmental conditions easily if the environment they live is changing.

Being a habitat specialist or generalist is expected to affect the strength of the relationship between occurrence and abundance, which should be stronger for habitat specialist species (Jiménez-Valverde et al. 2009). For instance, the jaguar is found in several types of habitats and the abundance-suitability relationship for this species is weak (Tôrres et al. 2012). A. caudifer is highly dependent of forested areas for feeding (Barquez \& Diaz 2008), so it

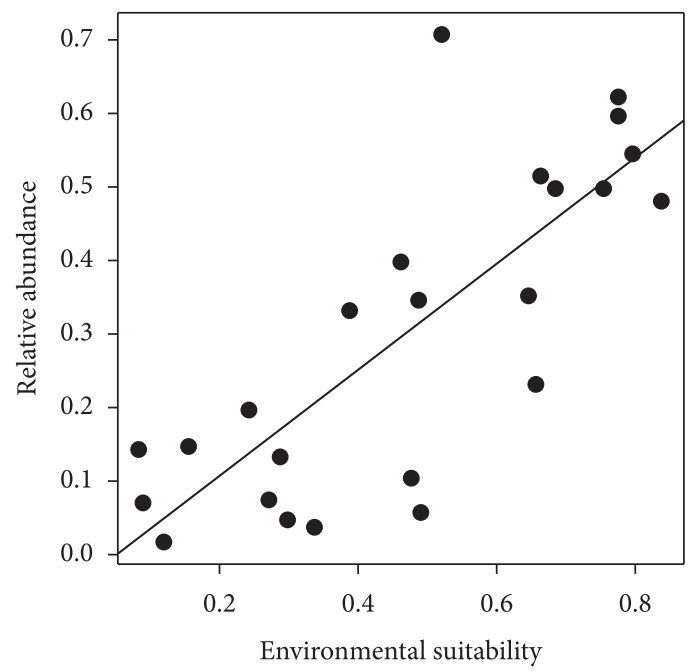

Figure 3. Linear regression analysis showing a positive and significant relationship between environmental suitability and relative abundance for the tailed tailless bat, Anoura caudifer $\left(R^{2}=0.64, P<0.001\right)$. can be considered as a habitat specialist. A homogenous resources distribution may reveal presence-absence patterns only, but it will not likely prove useful for modelling animal abundance (Nielsen et al. 2005). Therefore, considering that A. caudifer is a habitat specialist and its feeding resources (nectar) are not homogeneously distributed, these factors may explain better why this relationship is stronger for it than for habitat generalist species (as the jaguar studied by Tôrres et al. 2012). In addition, as nectar-feeding bats seem to relate similarly to their habitats, the positive relationship found for this common species may be applied to rare nectarivore bat species such as Data Deficient (e.g. Lonchophylla bokermanni) and Near Threatened species (e.g. Lonchophylla dekeyseri) guiding new surveys and finding unknown populations. We also might find similar abundance-suitability relationship for frugivore bat species because they are mostly forest-dependent and their food resources are patchy distributed. This relationship may not hold true for insectivore species because their food resources are scattered distributed. However, new studies including other species of these feeding guilds are needed to better support such hypothesis.

It is worth mentioning that we used data of relative abundance gathered from published bat community studies. This type of data can be affected by many factors such as environmental disturbance that can increase the abundance of generalist species and decrease abundance of sensitive species, differences in the season of bat sampling because nectar feeding bats are often subject to plant phenology, and undersampling effects that can make species abundance larger. Controlling all these effects is a hard job. However, it is possible control some of these sources of variation as we did here. Furthermore, despite these sources of variation, relative abundance still can be affected by climate conditions driving birth and death rates. Therefore, we believe that relative abundance data can be used to test the abundance-suitability relationship since the authors bear in mind these possible effects of variation. Moreover, relative abundance data are much easier to obtain than density data.

Despite some authors do not consider the relationship between suitability and abundance as a main pattern in ecology (e.g. Thuiller et al. 2010; Jiménez-Valverde 2011), probably due to the complexity of factors that can drive abundance at local scales, other studies have also found such a positive abundance-suitability relationship, although the predictive power is, in general, low (e.g. Pearce \& Ferrier 2001; VanDerWal et al. 2009; Kulhanek et al. 2011; Nabout et al. 2011; Tôrres et al. 2012). For example, VanDerWal et al. (2009) analyzed 69 vertebrate species (birds, amphibians, and reptiles) and the mean amount of variation explained was only $12 \%$. Similarly, Tôrres et al. (2012) found that environmental suitability explains only $33 \%$ of the jaguar's density variation. They assign this failure in predicting abundance from environmental suitability to the microscale variables such as local availability of sunlight (VanDerWal et al. 2009) or to anthropogenic actions such 
as hunting or deforestation (Tôrres et al. 2012) that were not included in the model. Other variables such as site history, scale (grain), sampling errors in abundance estimates or species life history may also influence the spatial variation in local abundance (Nielsen et al. 2005).

Furthermore, there are several methods to model species distribution and studies about abundance-suitability relationship are emerging, and we do not know which method performs better. Tôrres et al. (2012) pointed out that it is still unclear if more sophisticated methods will provide better density predictions. They found that, among the 11 ENM methods, the simplest method (BIOCLIM), presented the better ability to estimate density (33\%), with much lower value for more sophisticated methods, including Maxent. Here, however, we showed that suitability values provided by a more complex method (Maxent) were able to predict a large amount of abundance variation (64\%). Thus, we need more comprehensive studies about the differences among various methods of ENM in respect to the expected relationship between suitability and abundance, in order to understand in which circumstances each one works better and why (Tôrres et al. 2012).

Predicting abundance from presence data using ENM has broad implications for conservation biology, where environmental suitability is expected to change over time (VanDerWal et al. 2009) or to forecast both the occurrence and abundance patterns of invasive species at a regional scale (Kulhanek et al. 2011). When ENM suitability is correlated with spatial variation of abundance, we can use it as a proxy to forecast the impact of changing climate on abundance, or to define conservation priorities. This also has practical implications for ecologists gathering biological data, since obtaining abundance data is much more costly and time consuming than obtaining presence data. However, it is worth mentioning that generalizations from suitability predicting abundance should be taken with caution, because we still do not have a sufficient number of tests about this subject and more studies are needed (Nielsen et al. 2005; Jiménez-Valverde et al. 2009; Thuiller et al. 2010; Jiménez-Valverde 2011).

Finally, we suggest that ENM can be applied to rare nectarivore bat species as a surrogate to estimate abundance and to guide new surveys and to find unknown populations. For a more comprehensive understanding on spatial variation in bat species abundance we suggest that local variables such as richness of plant species that bats can feed on and size of fragments should also be considered in the analysis. Furthermore, researchers should analyze abundance-suitability relationship in a comparative context and take into account biological traits of bat species such as feeding habits, as well as the way that they are related to their habitats or environments (e.g. habitat specialist or generalist). This seems to be a promising way to understand the relationship between abundance and suitability, to make general ecological patterns and an invaluable application to species conservation in this changing world we are living in.

\section{Acknowledgements}

We thanks Cristina Araújo, José Alexandre and two reviewers for comments that improved this manuscript. To CAPES for scholarship to Marcelo de Moraes Weber, and to CNPq for Productivity fellowship to Carlos EV Grelle. Funding was provided by FAPERJ (Jovem Cientista do Estado) and Rede Clima program/MCT.

\section{References}

Arita HT, 1993. Rarity in Neotropical bats: correlations with phylogeny, diet, and body mass. Ecological Applications, 3:506-517. http://dx.doi.org/10.2307/1941919

Barquez R \& Diaz M, 2008. Anoura caudifer. In: IUCN 2012. IUCN Red List of Threatened Species. version 2012.2. Available from: <www.iucnredlist.org>. Access in: 03 Oct. 2012.

Brown JH, 1984. On the relationship between abundance and distribution of species. American Naturalist, 124:255-279. http://dx.doi.org/10.1086/284267

Dudík M, Phillips SJ \& Schapire RE, 2004. Performance guarantees for regularized maximum entropy density estimation. In: Proceedings of the 17th Annual Conference on Computational Learning Theory; 2004. Springer. p. 472-486.

Hijmans RJ et al., 2005. Very high resolution interpolated climate surfaces for global land areas. International Journal of Climatology, 25:1965-1978. http://dx.doi.org/10.1002/ joc. 1276

Jiménez-Valverde A, 2011. Relationship between local population density and environmental suitability estimated from occurrence data. Frontiers of Biogeography, 3:59-61.

Jiménez-Valverde A et al., 2009. Species distribution models do not account for abundance: the case of arthropods on Terceira Island. Annales Zoologici Fennici, 46:451-464. http://dx.doi.org/10.5735/086.046.0606

Krebs C, 2008. The Ecological World View. Melbourne: Csiro Publishing.

Kulhanek SA, Leung B \& Ricciardi A, 2011.Using ecological niche models to predict the abundance and impactof invasive species: application to the common carp. Ecological Applications, 21: 203-213. PMid:21516898. http://dx.doi. org/10.1890/09-1639.1

Legendre P \& Legendre L, 2003. Numerical ecology. Amsterdan: Elsevier.

Meyer CJF et al., 2011. Accounting for detectability improves estimates of species richness in tropical bat surveys. Journal of Applied Ecology, 48: 777-787. http://dx.doi. org/10.1111/j.1365-2664.2011.01976.x

Morrison ML, Marcot BG \& Mannan RW, 2006. Wildlife-Habitat Relationships: Concepts and Applications. Washington: Island Press.

Nabout, JC et al., 2011. Global climate change and the production of "Pequi" fruits (Caryocar brasiliensis) in the Brazilian Cerrado. Natureza \& Conservação, 9:55-59. http://dx.doi. org/10.4322/natcon.2011.006 
Nielsen SE et al., 2005. Can models of presence-absence be used to scale abundance? Two case studies considering extremes in life history. Ecography, 28:197-208. http:// dx.doi.org/10.1111/j.0906-7590.2005.04002.x

Pearce J \& Ferrier S, 2001. The practical value of modeling relative abundance of species for regional conservation planning: a case study. Biological Conservation, 98:33-43. http://dx.doi.org/10.1016/S0006-3207(00)00139-7

Pearson RG et al., 2007. Predicting species distributions from small numbers of occurrence records: a test case using cryptic geckos in Madagascar. Journal of Biogeography, 34:102-117. http://dx.doi.org/10.1111/j.1365-2699.2006.01594.x

Peterson AT et al., 2011. Ecological niches and geographic distribution. Princeton: Princeton University Press.

Phillips SJ, Anderson RP \& Schapire RE, 2006. Maximum entropy modelling of species geographic distributions. Ecological Modelling, 190:231-259. http://dx.doi.org/10.1016/j. ecolmodel.2005.03.026

Rangel TF, Diniz-Filho JAF \& Bini LM, 2010. SAM: a comprehensive application for Spatial Analysis in Macroecology. Ecography, 33:46-50. http://dx.doi. org/10.1111/j.1600-0587.2009.06299.x
Souza TV et al., 2011. Redistribution of threatened and endemic Atlantic Forest birds under climate change. Natureza \& Conservação, 9:214-218. http://dx.doi.org/10.4322/ natcon.2011.028

Taylor RAJ \& Taylor LR, 1979. A behavioural model for the evolution of spatial dynamics. In: Anderson RM, Turner BD \& Taylor LR (eds.). Population Dynamics. London: Blackwell. p. 1-27.

Thuiller W et al., 2010. Variation in habitat suitability does not always relate to variation in species' plant functional traits. Biology Letters, 6:120-123. PMid:19793738 PMCid:2817270. http://dx.doi.org/10.1098/rsbl.2009.0669

Tôrres NM et al., 2012. Can species distribution modelling provide estimates of population densities? A case study with jaguars in the Neotropics. Diversity and Distributions, 18:615-627. http://dx.doi.org/10.1111/j.1472-4642.2012.00892.x

United States Geological Survey - USGS, 2001. HYDRO 1K: Elevation Derivative Database. Available from: $<$ http://edc. usgs.gov/products/elevation/gtopo30/hydro/namerica.html>.

VanDerWal J et al., 2009. Abundance and the environmental niche: environmental suitability estimated from niche models predicts the upper limit of local abundance. American Naturalist, 174:282-291. PMid:19519279. http://dx.doi. org/10.1086/600087

Received: November 2012

First Decision: November 2012

Accepted: November 2012 